\title{
The Role of Additional Sex Combs-Like Proteins in Cancer
}

\author{
Jean-Baptiste Micol ${ }^{1,2,3}$ and Omar Abdel-Wahab ${ }^{3}$ \\ ${ }^{1}$ Hematology Department, INSERM UMR1170, Gustave Roussy Cancer Campus Grand Paris, Villejuif, France \\ ${ }^{2}$ Université Paris-Sud, Faculté de Médecine, Le Kremlin-Bicêtre, Paris, France \\ ${ }^{3}$ Human Oncology and Pathogenesis Program and Leukemia Service, Department of Medicine, Memorial \\ Sloan Kettering Cancer Center, New York, New York 10065 \\ Correspondence: abdelwao@mskcc.org
}

\begin{abstract}
Additional sex combs-like (ASXL) proteins are mammalian homologs of Addition of sex combs (Asx), a protein that regulates the balance of trithorax and Polycomb function in Drosophila. All three ASXL family members (ASXL1, ASXL2, and ASXL3) are affected by somatic or de novo germline mutations in cancer or rare developmental syndromes, respectively. Although Asx is characterized as a catalytic partner for the deubiquitinase Calypso (or BAP1), there are domains of ASXL proteins that are distinct from Asx and the roles and redundancies of ASXL members are not yet well understood. Moreover, it is not yet fully clarified if commonly encountered ASXL1 mutations result in a loss of protein or stable expression of a truncated protein with dominant-negative or gain-of-function properties. This review summarizes our current knowledge of the biological and functional roles of ASXL members in development, cancer, and transcription.
\end{abstract}

\begin{abstract}
dditional sex combs-like (ASXL) genes enAcode three proteins (ASXL1, ASXL2, and ASXL3), that share conserved domains and are orthologs of the Drosophila Additional sex combs (Asx) gene. Although the exact functions of ASXL family members are not well understood, cancer genomic studies identified highly recurrent somatic mutations in ASXL1 in 2009 and a series of studies have since revealed that these mutations are consistent predictors of adverse outcome (Bejar et al. 2011; Thol et al. 2011; Patel et al. 2012; Itzykson et al. 2013; Haferlach et al. 2014). Since then, recurrent mutations in ASXL2 and ASXL3 have been identified
\end{abstract}

in specific subsets of cancer and ASXL1/3 germline mutations have been found to underlie rare developmental syndromes. These findings have resulted in a great interest in understanding the function of each ASXL protein, the protein complexes they exist in, and their roles and redundancies in the development of normal and malignant cell types. In this review, we describe the discovery of mammalian ASXL genes and the mutations affecting each member. We also present a review and interpretation of the biochemical, epigenomic, and biological studies that have been performed to date to dissect their function.

Editors: Scott A. Armstrong, Steven Henikoff, and Christopher R. Vakoc

Additional Perspectives on Chromatin Deregulation in Cancer available at www.perspectivesinmedicine.org

Copyright (C) 2016 Cold Spring Harbor Laboratory Press; all rights reserved; doi: 10.1101/cshperspect.a026526

Cite this article as Cold Spring Harb Perspect Med 2016;6:a026526 


\section{DISCOVERY OF THE DROSOPHILA ADDITIONAL SEX COMBS (AsX) GENE}

As mentioned above, the mammalian ASXL genes derive their name from their Drosophila homolog Asx. Asx was originally discovered based on a genetic screen in Drosophila whereby mutations of Asx were found to enhance the phenotype of both Trithorax (TrxG) as well as Polycomb group (PcG) gene mutants (Fig. 1) (Sinclair et al. 1998; Milne et al. 1999). These phenotypes suggested that Asx is required to both maintain repression as well as activate expression of Hox genes in Drosophila. This dual function of Asx placed Asx as a member of the enhancer of Trithorax and Polycomb group (ETP) of genes, which are thought to mediate the balance between PcG and TrxG function.

Despite the fact that Asx was first uncovered 18 years ago, the molecular basis for its dual function in both repression as well as activation of Hox gene expression is not well understood. Asx encodes a chromatin-associated protein whose binding pattern to polytene chromosomes overlaps with PcG proteins (Sinclair et al. 1998). However, other than a welldescribed physical interaction with Calypso (termed BAP1 [BRCA1-associated protein 1] in mammalian cells) to oppose the function of the Polycomb repressive complex 1 (PRC1) (Scheuermann et al. 2010), the complexes that Asx participates in are not well defined (Fig. 2).

\section{DISCOVERY OF THE MAMMALIAN $A S X L$ GENE FAMILY}

Efforts to understand the molecular and structural basis for Asx's function as an ETP gene led to the discovery of mammalian homologs of Asx. Unlike Drosophila, mammals have 3 Asx homologs: ASXL1 (Fisher et al. 2003), ASXL2 (Katoh and Katoh 2003), and ASXL3 (Fig. 1) (Katoh and Katoh 2003). ASXL1, ASXL2, and ASXL3 are located on human chromosomes 20q11.21, 2p23.3, and 18q12.1, respectively. Phylogenetic analyses of the coding sequences of ASXL family members reveal that ASXL1 and ASXL2 orthologs are more closely related to one another than to ASXL3 (Katoh 2013). Although
ASXL1 and ASXL2 are widely expressed in mammalian tissues, ASXL3 expression is restricted to mostly the brain and the eye and is not appreciably expressed in hematopoietic cells (Fisher et al. 2006; Bainbridge et al. 2013; LaFave et al. 2015). There is $\sim 40 \%$ amino acid homology between ASXL1, ASXL2, and ASXL3 overall, but this homology increases to $~ 70 \%$ in the conserved domains of ASXL proteins including the ASXN, ASX homology (ASXH), ASXM1, and ASXM2 domains and the carboxyterminal cysteine cluster plant homedomain (PHD) (Fig. 3).

Mammalian ASXL family members each contain an ASXN domain located at the amino terminus, which is predicted to be a DNA-binding domain (Sanchez-Pulido et al. 2012). Interestingly, this domain is not present in $A s x$, suggesting an important divergence in function between $A s x$ and mammalian ASXL genes. The ASXH domain, in contrast, is highly homologous to the Drosophila DEUBAD (deubiquitinase adaptor) domain and corresponds to the BAP1 interaction site (Scheuermann et al. 2010). The ASXH domain is present in all three mammalian ASXL family members (Figs. 3 and 4), each of which have been recently shown to bind to BAP1 (Sahtoe et al. 2016). The ASXM1 and ASXM2 domains of ASXL proteins have been reported to bind to several nuclear hormone receptors (NHRs), including the androgen receptor (Grasso et al. 2012), estrogen receptor (Park et al. 2015), and PPARy (Park et al. 2011).

Currently, our knowledge of the function of ASXL1-3 is limited by a lack of systematic functional investigation of the conserved protein domains of ASXL family members. For example, although phylogenetic analyses suggest that the PHD domain of ASXL proteins may bind histone $\mathrm{H} 3$ lysine 4 trimethyl (H3K4me3) (Aravind and Iyer 2012; Katoh 2015), the function of the carboxy-terminal PHD domain of ASXL proteins is in need of definition. One recent report revealed that the $\mathrm{PHD}$ domain of ASXL2 binds H3K4me1 and H3K4me2, but validation of this finding with quantitative measurement of binding affinity and other confirmatory assays was not performed nor were the 

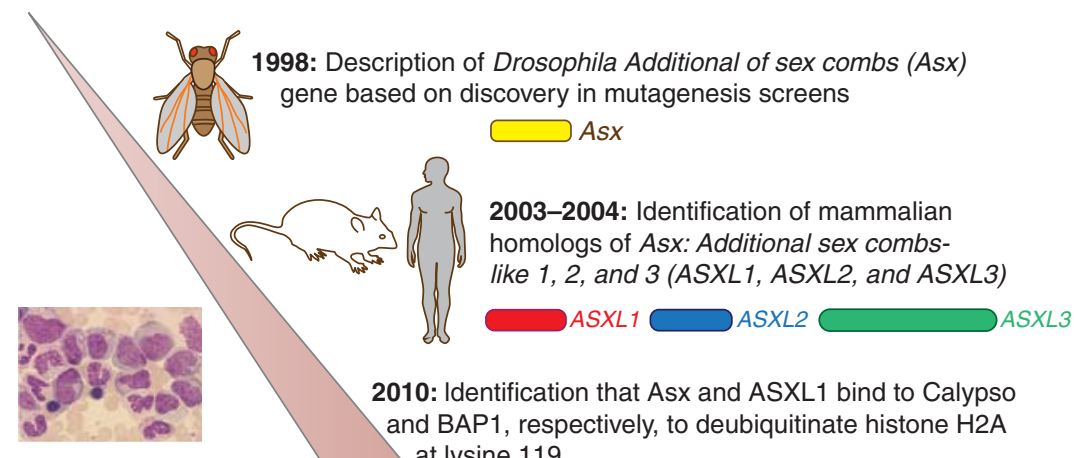

2009: Discovery of somatic and highly recurrent $A S X L 1$ mutations in myeloid

leukemias

2010: Identification that Asx and ASXL1 bind to Calypso and BAP1, respectively, to deubiquitinate histone $\mathrm{H} 2 \mathrm{~A}$ at lysine 119

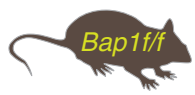

2012: Identification of Bap1 as a

tumor suppressor in myeloid leukemias 2012: Identification of effects
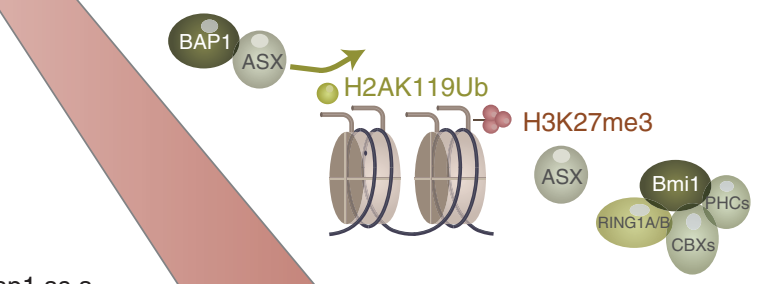

.

of ASXL1 loss on histone H3 lysine 27 trimethylation

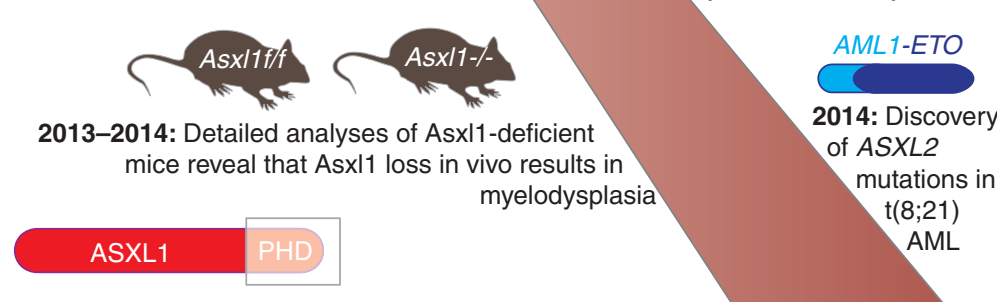

2013: Identification that overexpression of PHD-domain truncated forms of ASXL recapitulate biological effects of ASXL1 loss in vivo as well as global loss of H3K27me3

2015: Identification that overexpression of PHD-domain truncated forms of ASXL1 promote H2AK119 deubiquitinase activity of BAP1

Figure 1. Timeline of discovery of Additional sex combs-like family members and characterization of their effects on the epigenome, development, and cancer.

functions of ASXL1 or ASXL3 PHD domains studied (Park et al. 2015). Moreover, the possibility that the ASXL PHD domains may bind to nonhistone proteins remains to be tested.

In addition to further analysis of conserved domains of ASXL proteins, systematic exploration of the function of the domains that are not conserved between ASXL members needs to be performed. It is hypothesized that differing functions of these regions might endow each ASXL member with specialized functions in mammalian cells. Proteomic analysis of binding partners for each ASXL family member may be very helpful in identifying shared and unique binding partners for each ASXL family member in mammalian cells.

\section{DISCOVERY OF THE H2A DEUBIQUITINASE COMPLEX}

As noted above, ASXL members have been shown to interact with BAP1 through physical 
J.-B. Micol and O. Abdel-Wahab

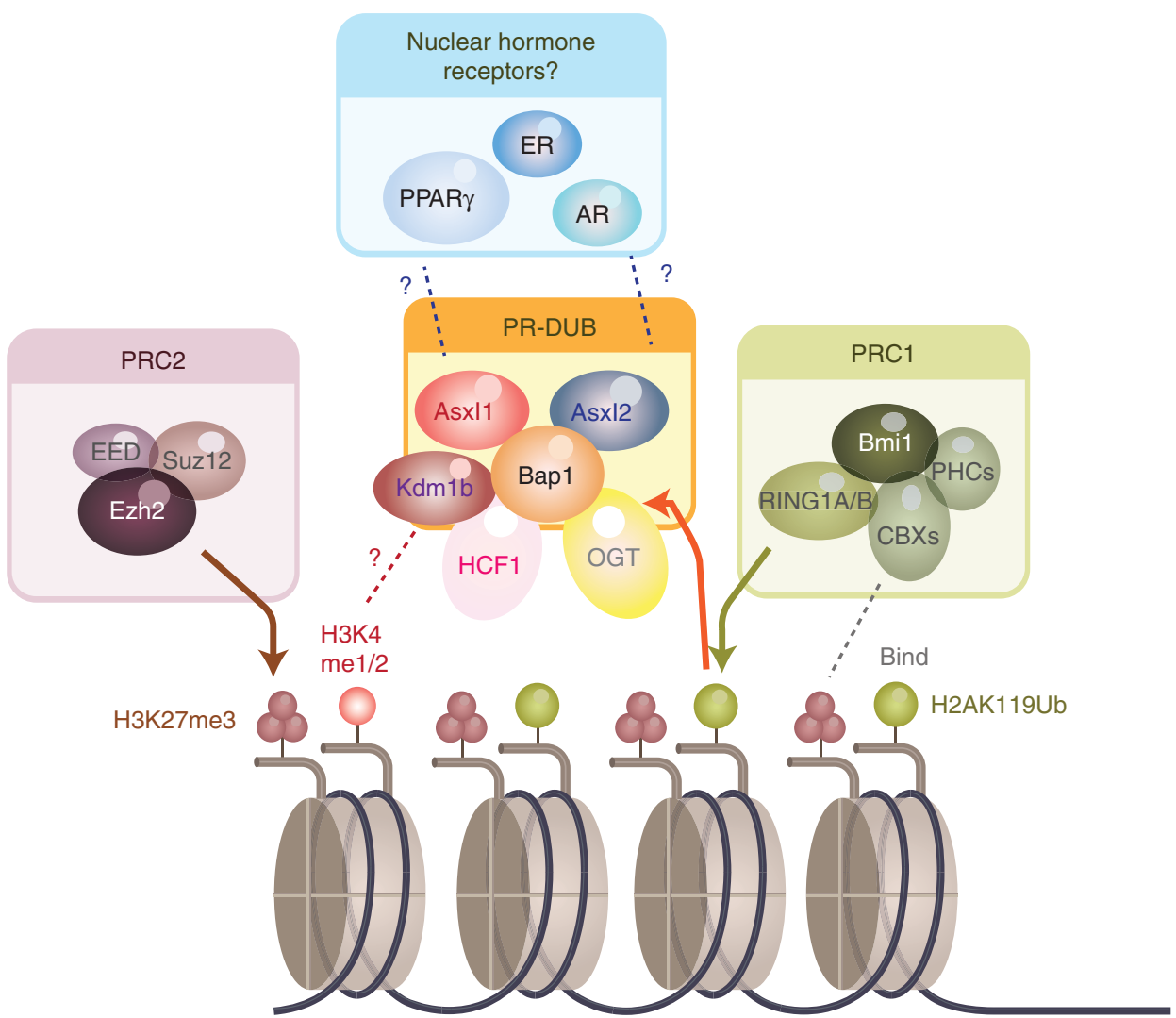

Figure 2. Known and proposed biochemical and epigenomic functions associated with Additional sex combslike (ASXL) family members. ASXL1 and ASXL2 have been copurified with BAP1 in numerous reports and serve as a deubiquitinase for histone H2A lysine 119 with BAP1 termed the Polycomb repressive deubiquitinase (PR-DUB). At least one report has suggested that ASXL1 and ASXL2 form mutually exclusive complexes with BAP1 in the PR-DUB. In addition, HCF1, OGT, and KDM1B all appear to be in complex with BAP1 as well. Whether the association of KDM1B with BAP1 has any influence on histone $\mathrm{H} 3$ lysine 4 mono- or dimethylation ( $\mathrm{H} 3 \mathrm{~K} 4 \mathrm{mel} / 2)$ is currently unclear. In addition, to opposing the function of the Polycomb repressive complex 1 (PRC1)-mediated H2AK119 ubiquitination, ASXL1 loss has also been repeatedly associated with global loss of histone $\mathrm{H} 3$ lysine 27 trimethylation (H3K27me3). Whether the H3K27me3 loss associated with ASXL1 loss is secondary to loss of H2AK119Ub and/or because of impaired Polycomb repressive complex 2 (PRC2) remains to be further clarified. Finally, ASXL1 and ASXL2 have been proposed to physically interact and/or functionally affect the function of a number of nuclear hormone receptors (NHRs) including PPAR $\gamma$ and the estrogen and androgen receptors (ER and AR, respectively).

interaction at the ASXH domain of ASXL proteins. BAP1 owes its name to its discovery as a protein that interacts with the RING finger domain of BRCA1 (Jensen et al. 1998). BAP1 contains as amino-terminal ubiquitin carboxyterminal hydrolase domain and was initially thought to be important in the deubiquitination of BRCA1 (a finding that has subsequently been disproven [Mallery et al. 2002]). Interest- ingly, in 2007, a forward genetic screen for mutations that cause loss of PcG repression in Drosophila identified Calypso, the ortholog of BAP1, as a novel PcG gene involved in repression of Hox genes (Gaytan de Ayala Alonso et al. 2007). As noted earlier, PcG proteins consist of several multiprotein complexes (the PRC1 and PRC2 complexes) that repress gene expression. PRC1 harbors an E3 ligase activity that 


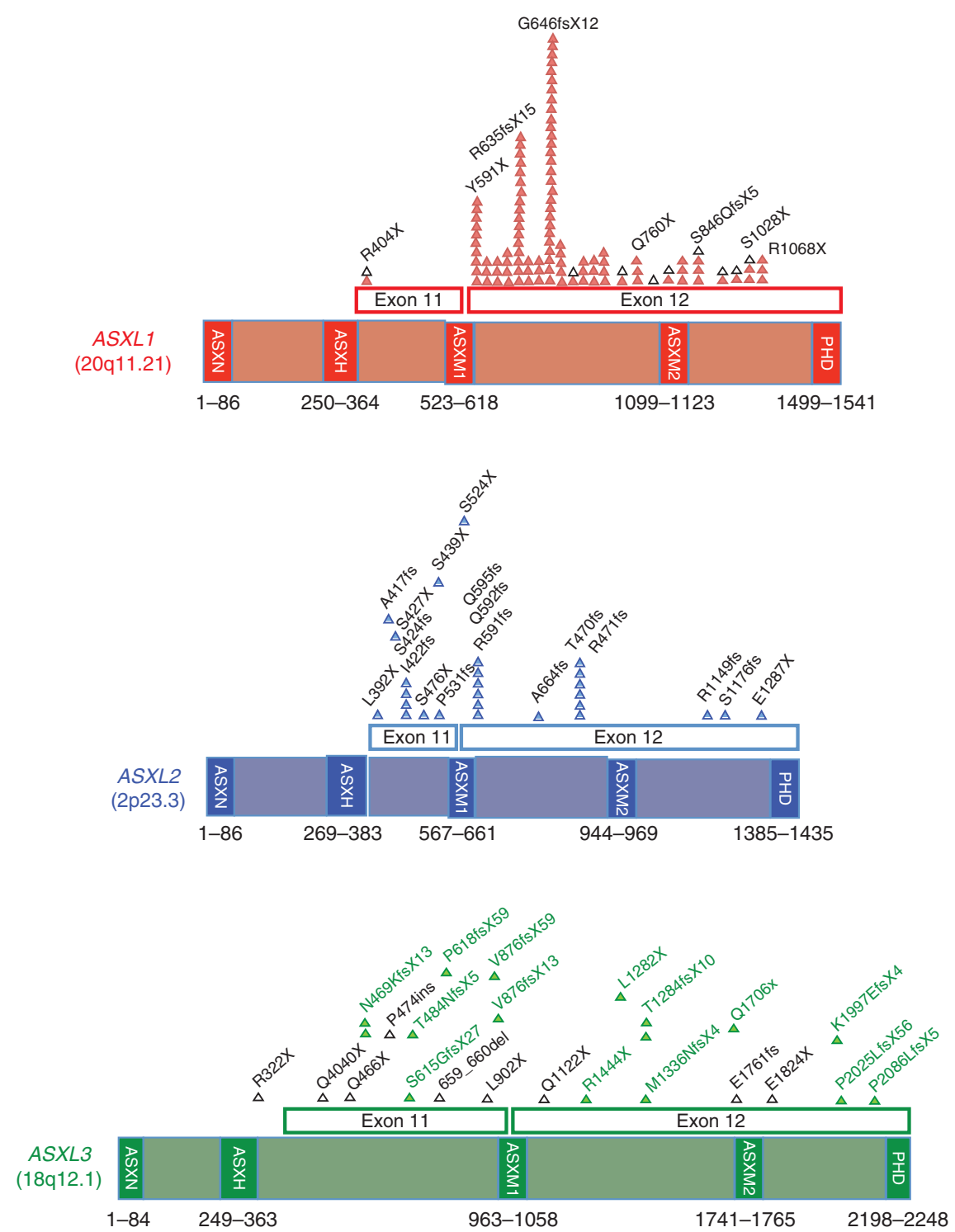

Figure 3. Protein domain structure and location of amino acids affected by mutations in ASXL1, ASXL2, and ASXL3. Only nonsense or frameshift mutations are shown for each protein here. Mutations shown in black triangles are previously reported as germline mutations in Bohring-Opitz syndrome (ASXL1) or BohringOpitz-like syndrome (ASXL3), whereas mutations in red, blue, or green triangles have been reported as somatic mutations in ASXL1, ASXL2, or ASXL3, respectively. For ASXL1, only somatic mutations that have been described in more than one patient or as a germline mutation are shown.

monoubiquitinates histone $2 \mathrm{~A}$ at lysine 119 (H2AK119). Biochemical characterization of BAP1 by Scheuermann et al. (2010) identified that BAP1 and ASXL1 coexist in a complex that they termed the Polycomb repressive deubiquitinase (PR-DUB) complex. They subsequently showed that BAP1 requires ASXL1 as a cofactor to deubiquitinate H2AK119Ub (Scheuermann et al. 2010). Consistent with this, Drosophila mutants lacking either Calypso or Asx had an increase in global H2AK119Ub (Scheuermann et al. 2010). 
J.-B. Micol and O. Abdel-Wahab

A

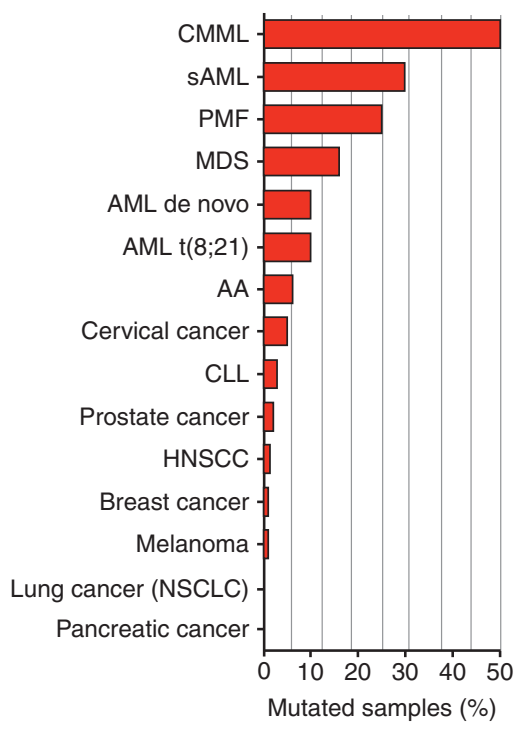

C

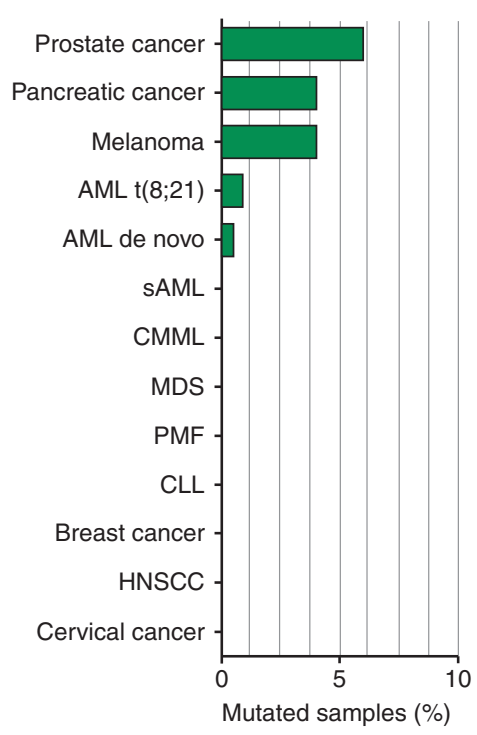

B

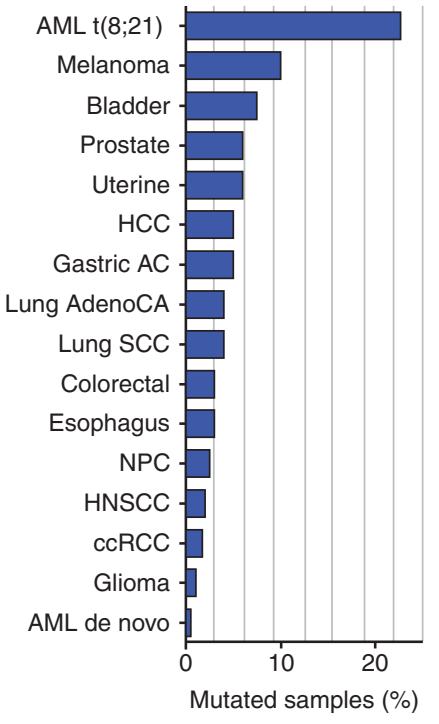

D

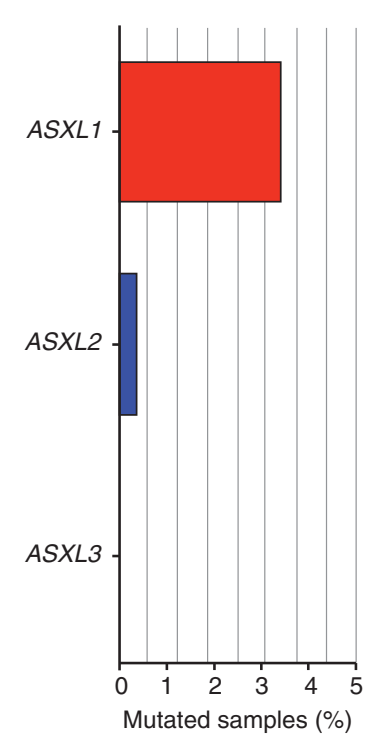

Figure 4. Histogram of somatic mutational frequency of $(A) A S X L 1,(B) A S X L 2$, and $(C) A S X L 3$ in cancer, as well as in $(D)$ clonal hematopoiesis of indeterminate potential. AA, Aplastic anemia; AML, acute myeloid leukemia; ccRCC, clear cell renal cell carcinoma; CMML, chronic myelomonocytic leukemia; CLL, chronic lymphocytic leukemia; HCC, hepatocellular carcinoma; HNSCC, head and neck squamous cell carcinoma; MDS, myelodysplastic syndromes; PMF, primary myelofibrosis; sAML, secondary AML.

The above data by Scheuermann et al. provided the first molecular function for $A s x$ and suggested that mammalian ASXL members might similarly function as cofactors for BAP1. However, unlike Drosophila, mammals have three ASXL members, and it is unclear how much redundancy in function occurs between each ASXL member in their interaction with BAP1. As mentioned earlier, the interaction between BAP1 and ASXL1 occurs through the ASXH domain. ASXH homology between ASXL family members is $\sim 60 \%$, and all three 
ASXL paralogs bind BAP1 and stimulate H2AK119 deubiquitination in vitro (Sahtoe et al. 2016).

In parallel to the discovery of BAP1's enzymatic function on H2AK119Ub, a tumor suppressor role of BAP1 became increasingly clear with genomic and functional investigation in cancer (reviewed recently by Carbone et al. 2013). BAP1 is located on 3 p21.1, a region deleted in multiple malignancies, including $30 \%-60 \%$ of mesothelioma and $40-65 \%$ of uveal melanoma patients. Subsequently, BAP1 was shown to be affected by germline mutations in mesothelioma (Testa et al. 2011) and melanoma (Harbour et al. 2010). More recently, the concept of BAP1 as a tumor suppressor was further extended after the description of BAP1 somatic mutations in a variety of additional cancer types (Carbone et al. 2013). This includes somatic BAP1 mutations in $40 \%$ of uveal melanoma (Harbour et al. 2010; Wiesner et al. 2011), 20\% of pleural mesothelioma (Bott et al. 2011; Testa et al. 2011), and 15\% of clear cell renal carcinoma (Bott et al. 2011; Guo et al. 2012) patients, respectively.

To clarify the role of BAP1 in mammalian development and cancer further, Dey et al. generated Bapl conditional knockout (cKO) mice as well as transgenic knockin mice expressing a 3xFlag tag (Dey et al. 2012). Proteomic analysis of BAP1 interacting partners using this system revealed that BAP1 interacts with ASXL1 and ASXL2 in vivo as well as host cell factor 1 (HCF-1), O-GlcNAc transferase (OGT), and Forkhead box protein K1/2 (FOXK1/2) (Dey et al. 2012). Similar results were seen with proteomic analysis of FLAG-HA tandem purification of tagged BAP1 and ASXL1 expressed in 293T cells more recently (Wu et al. 2015). In addition, the mass spectrometric analysis by Dey et al. (2012) also identified a physical interaction between BAP1 and the $\mathrm{H} 3 \mathrm{~K} 4$ demethylase KDM1B (also known as LSD1B), an intriguing interaction that might implicate BAP1/ASXL in KDM1B function and will need to be validated further.

Despite the above analyses of interaction partners between BAP1 and ASXL1/2 in mammalian cells, it is not clear how much of the function of ASXL1 or ASXL2 relates to the function of BAP1 and other members of the BAPASXL complexes, which have been identified. Unlike Drosophila, lack of ASXL1 in mammalian cells has not been clearly linked to changes in H2AK119Ub (Abdel-Wahab et al. 2012), possibly because of redundancies of multiple ASXL members in mammalian cells. Moreover, murine models with $\mathrm{cKO}$ of $B a p 1$ versus $A s x l 1$ (described below) show distinct phenotypes. Finally, there is a lack of obvious clinical overlap of diseases involving mutations in BAP1 versus $A S X L 1$. Each of these findings suggests some potential independent roles of BAP1 and ASXL1.

\section{DISCOVERY OF MUTATIONS IN ASXL GENE FAMILY MEMBERS IN CANCER}

Investigations into the mechanistic function and biological roles of ASXL proteins increased tremendously with the discovery of frequent somatic mutations in ASXL1 in patients with myeloid leukemias (Gelsi-Boyer et al. 2009). Further sequencing efforts have since identified that ASXL1 mutations are highly recurrent throughout all myeloid leukemias (Figs. 3 and 4). Mutations affecting ASXL1 most frequently occur as heterozygous frameshift or nonsense mutations, usually in exons 11 or 12 , just before the PHD domain. In addition, the locus of ASXL1, 20q11.21, is occasionally affected by somatic deletions in myeloid leukemias. Moreover, clinical correlative analyses have repeatedly identified that ASXL1 mutations predominate in older patients and are linked to an adverse outcome independent of other known clinical prognosticators (Bejar et al. 2011; Thol et al. 2011; Patel et al. 2012; Itzykson et al. 2013; Haferlach et al. 2014).

The human disorder in which ASXL1 mutations appear to be most frequent is chronic myelomonocytic leukemia (CMML), a disease with overlapping features of myeloproliferative neoplasms (MPNs) and myelodysplastic syndromes (MDSs). ASXL1 mutations are present in $40 \%-50 \%$ of CMML patients and appear to be a unique predictor of adverse outcome in this disease (Itzykson et al. 2013). 
Similar to CMML, ASXL1 mutations have been shown to be important biomarkers of adverse outcome in the MPNs, MDSs, and acute myeloid leukemia (AML). Although ASXL1 mutations are infrequent in the chronic and relatively benign MPNs essential thrombocytosis (ET) and polycythemia vera (PV), they are enriched in those PV/ET patients who experience transformation to a more aggressive clinical state known as myelofibrosis (MF) (Stein et al. 2011).

In MDS, ASXL1 mutations represent one of the most frequent gene mutations and are present in $10 \%-25 \%$ of patients (Figs. 3 and 4) (Bejar et al. 2011; Thol et al. 2011; Haferlach et al. 2014). Interestingly there appears to be an enrichment of ASXL1 mutations in AML patients with a history of preceding MDS (Fernandez-Mercado et al. 2012) or in AML with MDSrelated changes (Devillier et al. 2015) compared with de novo AML. In AML, ASXL1 mutations are 4-5 times more likely in older patients, explaining the discrepancy in ASXL1 mutational frequencies reported across AML sequencing studies (Metzeler et al. 2011). Consistent with this, ASXL1 mutations have been repeatedly identified in individuals with clonal hematopoiesis of indeterminate potential, a condition whose frequency increases with advanced age (Genovese et al. 2014; Jaiswal et al. 2014; Xie et al. 2014).

Very recently, several studies have identified that ASXL1 and ASXL2 mutations are enriched in a very specific subset of AML, AML with t(8;21) (Huether et al. 2014; Duployez et al. 2015b), which represent $\sim 10 \%$ of all AML. ASXL family member mutations occur in $\sim 30 \%$ of pediatric and adult $\mathrm{t}(8 ; 21)$ AML patients (Figs. 3 and 4) (Micol et al. 2014). This high frequency is mainly a result of ASXL2 mutations $(23 \%)$, which are otherwise almost never observed in other forms of leukemia. Interestingly, ASXL1 and ASXL2 mutations are mutually exclusive in $t(8 ; 21)$ AML suggesting that the mutations may have convergent downstream and/or are synthetic lethal effects with one another. A recent targeted mutational analysis of $t(8 ; 21)$ AML suggests that these mutations are also mutually exclusive with mutations in other epigenetic modifiers, such as EZH2, and when associated with tyrosine kinase mutations are associated with an increased risk of relapse (Duployez et al. 2016). In sequencing analysis of $\mathrm{t}(8 ; 21)$ AML, a single patient with an ASXL3 mutation has been described but otherwise ASXL3 mutations have been very infrequently reported in hematological malignancies (Duployez et al. 2015a).

ASXL1 mutations have also been described recently in additional rare myeloid malignancies including aplastic anemia (Yoshizato et al. 2015), chronic neutrophilic leukemia (Elliott et al. 2015), and systemic mastocytosis (Damaj et al. 2014). They have also been described as secondary somatic events in patients with hereditary hematological malignancies because of congenital GATA2 deficiency (Micol and AbdelWahab 2014; West et al. 2014) and congenital neutropenia (Beekman et al. 2012). In contrast to their frequency in myeloid disorders, $A S X L$ mutations have only been sporadically observed in lymphoid malignancies, being noted in very rare cases of chronic lymphocytic leukemia (Quesada et al. 2012) and acute lymphoblastic leukemia (Prebet et al. 2013).

\section{DISCOVERY OF MUTATIONS IN ASXL GENE FAMILY MEMBERS IN DEVELOPMENTAL DISORDERS}

In addition to somatic mutations of $A S X L$ family members in cancer, de novo germline ASXL mutations have been recently discovered to underlie developmental disorders as well. In particular, ASXL1 mutations have been described in $\sim 50 \%$ of patients with BohringOpitz syndrome (BOS) (Hoischen et al. 2011; Magini et al. 2012; Avila et al. 2013; Dangiolo et al. 2015), a rare disease defined by distinctive craniofacial features, intellectual disability, and severe feedings problems. ASXL1-mutant BOS patients appear to have specific clinical characteristics, including myopia and hypertrichosis, compared with ASXL1 wild-type patients (Magini et al. 2012). ASXL3 mutations have also been discovered in patients with a BOS-like syndrome, a close but distinct congenital disorder (Bainbridge et al. 2013; Dinwiddie 
et al. 2013; Srivastava et al. 2015). Moreover, no ASXL3 mutations have been found in BOS patients wild-type for ASXL1 (Russell and Graham 2013), suggesting true genetic differences between BOS and BOS-like conditions.

Interestingly, heterozygous nonsense and out-of-frame frameshift germline mutations in ASXL1 and ASXL3 occur exclusively in the two last exons of these two genes, exactly as seen as with somatic mutations affecting these genes in patients with cancer (Fig. 3). Despite this, and in contrast to patients with germline BAP1 mutations, patients with BOS and BOS-like conditions have not been identified to have consistently increased risk of cancer. Given that only $\sim 50$ patients with BOS have been described and that BOS patients frequently die as infants, cancer risk associated with this syndrome is not well defined. However, BOS syndrome patients have been reported to have nephroblastomatosis, meduloblastoma, and Wilms tumor, suggesting that germline ASXL1/3 mutations could increase the risk for cancer predisposition (Russell et al. 2015).

\section{PHENOTYPIC ANALYSES OF $A S X L$ FUNCTION IN VIVO}

To understand the role of ASXL family members in mammalian development and cancer further, a number of murine models targeting the expression of Asxl family member have been described. Currently, gene-trap constitutive $\mathrm{KO}$ models as well as cKO models have been described for Asxl1 and Asxl2 and no murine models targeting Asxl3 have been described ( $\mathrm{Ta}$ ble 1). These mice have been helpful in elucidating the effects of Asxl1 versus Asxl2 on tissue development. Constitutive homozygous loss of Asxll is associated with partial (Fisher et al. 2010a,b; McGinley et al. 2014; Wang et al. 2014) to complete embryonic lethality (Abdel-Wahab et al. 2013) depending on the model. Constitutive Asxl1-deficient mice display developmental abnormalities including dwarfism and anophthalmia, features not shared by Asxl2 KO mice (Baskind et al. 2009). Asxl2 KO mice, in contrast, die in the first few days following birth because of failure to close the ductus arteriosus inducing fatal pulmonary hypertension (McGinley et al. 2014). Both Asxl1 and Asxl2 $\mathrm{KO}$ mice have alterations of the axial skeleton with posterior (PcG phenotype) and anterior (TrxG phenotype) transformations, analogous to the effects of Asx loss in Drosophila described earlier (Sinclair et al. 1998; Milne et al. 1999). At least two prior studies have noted that ASXL1 and ASXL2 are important mediators of the function of the nuclear receptor PPAR $\gamma$ in adipogenesis (Park et al. 2011; Izawa et al. 2015). Consistent with this, Asxl2 KO mice appear to develop osteopetrosis, lipodystrophy, and insulin resistance because of a failure of PPAR $\gamma$ activation (Table 1) (Izawa et al. 2015). Given data that ASXL1 and ASXL2 may have opposing roles in adipogenesis based on in vitro fat differentiation assays (Park et al. 2011), it would be important to determine whether Asxl1 KO mice have alterations in metabolism and bone metabolism as well. Finally, Asxl1 KO mice have also been reported to have defects in kidney size and glomerular podocyte formation because of impaired WT1 signaling in early kidney development (Moon et al. 2015).

Shortly after the discovery of somatic ASXL1 mutations in myeloid leukemias, the in vivo effects of Asxl1 alterations on hematopoiesis were studied using Asxll gene-trap mice (Table 1) (Fisher et al. 2010b). In an initial report, postnatal hematopoietic cells as well as fetal liver hematopoietic cells from surviving Asxll KO mice were found to have defects in B- and Tlymphopoiesis as well as myeloid skewing but were not found to develop overt leukemia or lymphoma. At the same time, results of competitive or serial transplantation assays were not reported. Thus, comprehensive assessment of the effects of Asxl1 loss on hematopoietic stem cell function and self-renewal were not clear from this study (Fisher et al. 2010b). In contrast to these data, longitudinal analysis of another Asxl1 KO model identified that mice deficient for Asxl1 developed pancytopenia and morphologic dysplasia (Table 1) (Wang et al. 2014). Moreover, these features were also present in mice with heterozygous deletion of Asxl1 suggesting that Asxl1 may serve as a haploinsuffi- 
J.-B. Micol and O. Abdel-Wahab

Table 1. Germline genetically engineered murine models investigating the function of ASXL family members in cancer and development

\begin{tabular}{|c|c|c|c|}
\hline Mouse model & Biological phenotype & Epigenetic alterations & References \\
\hline$A s x l 1^{\operatorname{tmlBc}}$ mutant & $\begin{array}{l}\text { Partial embryonic lethality, alterations } \\
\text { of the axial skeleton, early death, } \\
\text { reduction in body weight and } \\
\text { thymus, splenomegaly; defects in } \\
\text { frequency of differentiation of } \\
\text { lymphoid and myeloid progenitors } \\
\text { but no hematological phenotype }\end{array}$ & $\begin{array}{l}\text { Hoxa4 and Hoxa7 } \\
\text { repression }\end{array}$ & $\begin{array}{l}\text { Fisher et al. } \\
\text { 2010a,b }\end{array}$ \\
\hline$E I I a$-cre $A s x l 1^{\mathrm{fl} / \mathrm{fl}}$ & $\begin{array}{l}100 \% \text { embryonic lethality, craniofacial } \\
\text { abnormalities }\end{array}$ & Not described & $\begin{array}{l}\text { Abdel-Wahab } \\
\text { et al. } 2013\end{array}$ \\
\hline$M x 1$-cre $A s x l 1^{f l / f l}$ & MDS-like phenotype; aggressive MDS & $\begin{array}{l}\text { Reduced global } \\
\text { H3K27me3, increase } \\
\text { expression of HoxA } \\
\text { genes }\end{array}$ & \\
\hline $\begin{array}{l}\text { Asxl1 } \\
\qquad \text { (Asxl1:nlacZ/nGFP) }\end{array}$ & $\begin{array}{l}80 \% \text { embryonic lethality, } 78 \% \text { of newborn } \\
\text { died after } 1 \text { day, developmental } \\
\text { abnormalities; MDS-like disease }\end{array}$ & Not described & Wang et al. 2014 \\
\hline $\begin{array}{l}\text { Asxl1 } 1^{+/-} \\
\quad(\text { Asxl1:nlacZ/nGFP) }\end{array}$ & $\begin{array}{l}\text { Haploinsufficiency sufficient for the } \\
\text { development of MDS-like and MDS/ } \\
\text { MPN-like disease }\end{array}$ & $\begin{array}{l}\text { Increased expression of } \\
\text { HoxA genes }(\text { HoxA5, } \\
\text { 7,9, and 10); } \\
\text { decrease of global } \\
\text { levels of H3K27me3 } \\
\text { and H3K4me3 }\end{array}$ & \\
\hline Asxl1 ${ }^{t m l a}$ & $\begin{array}{l}\text { Partial embryonic lethality, reduced } \\
\text { body weight and display cleft palate, } \\
\text { anophthalmia, ventricular septal } \\
\text { defects, lung defects }\end{array}$ & Not described & $\begin{array}{l}\text { McGinley et al. } \\
2014\end{array}$ \\
\hline Asxl1-null mice & $\begin{array}{l}\text { Defects in kidney size and glomerular } \\
\text { podocyte morphology }\end{array}$ & Not described & Moon et al. 2015 \\
\hline Germline $B a p 1^{-/-}$ & Embryonic lethality & Not described & Dey et al. 2012 \\
\hline Cre-ERT2 Bap $1^{f l / f l}$ & MDS/CMML-like disease & & \\
\hline $\begin{array}{l}\text { Asxl2 gene trap mutant } \\
\quad \text { mice } \\
\quad(\text { Asxl2Gt }(A Q 0356))\end{array}$ & $\begin{array}{l}\text { Partially embryonic lethal, } \\
\text { transformation in the axial skeleton, } \\
\text { reduced body weight, congenital } \\
\text { heart malformations, low bone } \\
\text { mineral density, osteopetrosis, } \\
\text { lipodystrophy, insulin resistance }\end{array}$ & $\begin{array}{l}\text { Reduction in the bulk } \\
\text { level of H3K27me3 } \\
\text { in cardiac tissue }\end{array}$ & $\begin{array}{l}\text { Baskind et al. } \\
\text { 2009; Farber } \\
\text { et al. 2011; Lai } \\
\text { et al. 2012; Lai } \\
\text { and Wang } \\
\text { 2013; Izawa } \\
\text { et al. } 2015\end{array}$ \\
\hline$M x 1$-cre $A s x l 2^{f l / f l}$ & $\begin{array}{l}\text { Cytopenias (leukopenia, } \\
\text { thrombocytopenia), defect in } \\
\text { hematopoietic self-renewal }\end{array}$ & $\begin{array}{l}\text { Reduction in } \\
\text { H3K4me1 }\end{array}$ & Micol et al. 2015 \\
\hline
\end{tabular}

CMML, Chronic myelomonocytic leukemia; MDS, myelodysplastic syndrome; MPN, myeloproliferative neoplasm.

cient tumor suppressor in the hematopoietic system (Wang et al. 2014).

Given the early lethality associated with constitutive Asxl1 loss and the need to study the effects of Asxll loss in a hematopoietic-specific manner following postnatal development, we developed a cKO Asxl1 model (Abdel-Wahab et al. 2013). Mice with hematopoietic-specific deletion of Asxl1 (Vav-cre Asxl1 ${ }^{f l f l}$ mice) as well as postnatal, inducible deletion of Asxl1 (Mxl-cre Asxlf ${ }^{f l / f l}$ mice) were observed to develop progressive multilineage cytopenias and 
dysplasia with increased numbers of hematopoietic stem and progenitor cells (HSPCs) with impaired mature cell differentiation-features consistent with the human disease MDS (Table 1). These features were further apparent in mice with hematopoietic-specific deletion of both Tet2 and Asxl1 (Abdel-Wahab et al. 2013), a combined genetic alteration present in $\sim 30 \%$ of patients with CMML (Itzykson et al. 2013) and $15 \%$ of patients with high-risk MDS (Bejar et al. 2011).

The above data suggest that Asxll functions as a haploinsufficient tumor suppressor in the hematopoietic system. Consistent with these germline genetically engineered murine models of Asxl1 loss, we had also previously observed that RNAi-mediated depletion of Asxll in a murine retroviral bone marrow transplant (BMT) assay with concomitant overexpression of NRasG12D resulted in a disorder with features of MDS/MPN in vivo (Abdel-Wahab et al. 2012). Despite these data, the nature of ASXL1 mutations as heterozygous mutations in a restricted domain have suggested that ASXL1 mutations might confer a gain-of-function, rather than loss-of-function, by generating a stable truncated protein lacking the carboxy-terminal PHD domain that either serves as a dominantnegative function or generates a new function. To this end, Inoue et al. performed a series of in vitro and in vivo experiments with retroviral overexpression of cDNA bearing ASXL1 truncated forms (Inoue et al. 2013). Overexpression of truncated forms of ASXL1 in a murine BMT model along with NRASG12D was found to result in a phenotype very similar to that seen with Asxl1 loss as described earlier (Abdel-Wahab et al. 2012). These results suggest that ASXL1 mutations might confer a dominantnegative function mimicking the biological effects of complete ASXL1 loss. However, further efforts to define the actual function of the ASXL1 PHD domain and to directly compare complete loss of ASXL1 versus expression of mutant ASXL1 from its endogenous locus are still needed to clarify the functional impact of ASXL1 mutations.

In contrast to the time-dependent bone marrow failure identified with hematopoietic- specific deletion of Asxl1 in vivo, hematopoietic-specific deletion of Bap1 in vivo has been found to result in an abrupt and aggressive disease with features of MDS and MPN (Dey et al. 2012). The discrepant phenotype between loss of Bap1 versus Asxl1 in vivo suggests that loss of Asxll function may be compensated for by its paralog Asxl2 and/or that Bap1 and Asxl1 affect hematopoiesis through divergent downstream effects. To address the potential role of Asxl2 in hematopoiesis, we recently generated Asxl2 cKO mice to study the effects of postnatal deletion of Asxl2 on hematopoiesis (Micol et al. 2015). Interestingly, Asxl2 cKO mice $\left(M \times 1\right.$-cre Asxl2 $\left.{ }^{f l / f l}\right)$ develop cytopenias and impairments in HSPC self-renewal, which are far more apparent than seen with Asxl1 cKO $\left(M x 1\right.$-cre Asxl1 $\left.{ }^{f l / f l}\right)$ studied in parallel (Micol et al. 2015). These data suggest that ASXL1 and ASXL2 have nonoverlapping effects in hematopoiesis.

\section{EFFECT OF ASXL MUTATIONS ON ASXL FUNCTION}

Despite 7 years of research on ASXL1 mutations in cancer now, it is still not entirely clear whether the recurrent nonsense and frameshift mutations affecting ASXL1 result in a loss of ASXL1 protein expression or expression of a stable, truncated form of ASXL1 lacking the carboxyterminal PHD domain. We previously failed to detect any ASXL1 protein expressed in cell lines bearing homozygous truncating mutations in ASXL1 (Abdel-Wahab et al. 2012). Moreover, we noted reduced full-length ASXL1 protein expression in cell lines bearing heterozygous ASXL1 mutations without any evidence of truncated ASXL1 protein forms. These data suggested that ASXL1 mutations are associated with nonsense-mediated decay and loss-of-function. Consistent with this, the expression of ASXL1 mutants in the presence of cyclohexamide results in a rapid degradation of the proteins suggesting reduced stability of the mutant proteins (Abdel-Wahab et al. 2012).

In contrast to the above, Inoue et al. (2015) used new amino-terminal anti-ASXL1 antibodies and mTRAQ-based mass spectrometric 
analysis in an effort to detect potential truncated ASXL1 proteins. Interestingly, truncated forms of ASXL1 were detected in two cell lines bearing homozygous truncating ASXL1 mutations that had not previously been studied. Nonetheless, it is not clear whether such truncated proteins are recurrently found in cells bearing ASXL1 mutations or how stable these truncated proteins are. To this end, recent work by Inoue et al. has also identified that ASXL1 protein stability appears to be mediated in part by ubiquitination at residue lysine 351 (K351). Interestingly, K351 is deubiquitinated, not by BAP1, by the deubiquitinase USP7 (Inoue et al. 2015). Further efforts to manipulate the expression of wild-type versus mutant ASXL1 by mutating the K351 residue of ASXL1 may help elucidate the function of endogenous mutations in ASXL1. In addition, efforts to introduce an easily detectable epitope tag into the amino terminus of the ASXL1 locus in cells with endogenous ASXL1 mutations may likewise be extremely helpful in understanding the effect of ASXL1 mutations on expression of ASXL1.

Although both ASXL1 and ASXL2 have been identified to bind to BAP1, recent biochemical characterization of BAP1 complexes by Daou et al. (2015) suggest that BAP1 forms two mutually exclusive complexes with ASXL1 and ASXL2. In this study, BAP1 was identified to stabilize ASXL2 via deubiquitination of ASXL2. Consistent with this, the protein level of ASXL2, but not ASXL1, was clearly dependent on BAP1 abundance (Daou et al. 2015). These data suggest that loss of ASXL2 function may consistently accompany BAP1 mutations and deletions, adding further importance to understanding the role of ASXL2 loss on cancer pathogenesis.

\section{ROLE OF ASXL PROTEINS IN H2A DEUBIQUITINATION}

As noted earlier, phenotypic analyses in vitro and in vivo have suggested that overexpression of stable truncated forms of ASXL1 appear to result in similar biological phenotypes as seen with ASXL1 loss (Inoue et al. 2013). To understand the potential mechanistic effects of ex- pression of PHD-domain truncated forms of ASXL1, Balasubramani et al. recently studied the effects of overexpression of ASXL1 truncated forms on H2AK119Ub. Overexpression of several truncated forms of ASXL1, but not full-length ASXL1, in combination with overexpression of BAP1 resulted in clear depletion of global H2AK119Ub as well as a striking reduction of histone $\mathrm{H} 3$ lysine 27 trimethylation (H3K27me3) (Balasubramani et al. 2015). Despite these results suggesting that ASXL1 truncation mutants might serve a gain-of-function mutations by hyperactivating PR-DUB activity, it is important to note that these experiments were performed using overexpression of both the enzymatic deubiquitinase as well as truncated forms of ASXL1 - neither of which are clearly overexpressed in cells bearing these mutations. Moreover, the effects of loss of ASXL1 were not assessed in parallel with expression of the truncated forms of ASXL1 and, thus, it is unclear whether these mutations might actually confer a dominant negative activity. Future efforts to study the epigenomic and biological effects of isogenic cells with engineered mutations in the endogenous locus of ASXL1 will hopefully clarify the effects of physiologic expression of these mutations further.

\section{ROLE OF ASXL PROTEINS AND BAP1 IN PRC2 FUNCTION}

In addition to potential effects on H2A deubiquitination, ASXL1 mutations have also been linked to alterations in PRC2 function as a result of the repeated observation of changes in H3K27 methylation in the setting of ASXL1 loss or mutation (Abdel-Wahab et al. 2012, 2013; Inoue et al. 2013; Wang et al. 2014; Balasubramani et al. 2015). Although work from our group (Abdel-Wahab et al. 2012) and others (Inoue et al. 2013) suggested that ASXL1 loss was associated with loss of H3K27me because of altered EZH2 recruitment at key loci, more recent work has suggested that this alteration in H3K27 methylation with ASXL1 loss is not because of direct interaction between ASXL1 and PRC2 components (Wu et al. 2015). In contrast, Balasubramani et al. suggest that the depletion 
of $\mathrm{H} 3 \mathrm{~K} 27 \mathrm{me} 3$ seen in the presence of $A S X L 1$ alterations may be secondary to depletion of H2AK119Ub and subsequent failure of PRC2 recruitment (Balasubramani et al. 2015). It is also important to note recent work identifying that EZH2 activity is also required for malignant transformation mediated by BAP1 loss in several tissue types (LaFave et al. 2015). These data underlie a relationship between PR-DUB and PRC2 function. Further efforts to analyze the genome-wide binding of ASXL1 as well as the binding of PRC2 components in the presence and absence of ASXL1 will hopefully help to elucidate the effects of ASXL1 alterations on PRC2 localization.

\section{CONCLUSIONS}

The majority of our understanding of ASXL family members to date emanates from analyses of ASXL1 and BAP1 function and mutations. However, it is not clear exactly how much of the function of ASXL1 in vivo relates to serving in an enzymatic complex with BAP1 versus other functions in regulating PRC2 activity and/or the function of other nuclear receptors. Further effort to understand the protein complexes that each ASXL family member participates in as well as the biological functions of each ASXL family member in vivo will be critical in understanding the roles and potential redundancies of each protein. In addition, efforts to study cells with engineered mutations in the endogenous locus of ASXL1 to model human-disease-associated alterations will be critical. Given the clinical importance of ASXL1 mutations in myeloid leukemias, knowledge of the precise effect of these mutations may be important in efforts to therapeutically target the downstream effects of ASXL1 mutations and/or the mutant ASXL1 protein itself (if such a protein is actually stably expressed in cells). Indeed, recent work using genome editing to correct a homozygous ASXL1 nonsense mutation in vivo suggests that restoring normal expression of ASXL1 may have important therapeutic implications for leukemia (Valletta et al. 2015). Along these same lines, it will be critically important to define the function of each ASXL member's
PHD domain, given the hypothesis that removal of the ASXL1/2 PHD domain may alone be pathogenic.

\section{ACKNOWLEDGMENTS}

J.-B.M. is supported by a grant from the Fondation de France. O.A.-W. is supported by grants from the National Institutes of Health (NIH) (R01 HL128239), the Edward P. Evans Foundation, and the United States Department of Defense Bone Marrow Failure Research Program (W81XWH-12-1-0041 and BM150092), the NIH (1K08CA160647-01), the Josie Robertson Investigator Program, the Damon Runyon Foundation, the Starr Foundation, and the Center for Experimental Therapeutics at Memorial Sloan Kettering Cancer Center.

\section{REFERENCES}

Abdel-Wahab O, Adli M, LaFave LM, Gao J, Hricik T, Shih AH, Pandey S, Patel JP, Chung YR, Koche R, et al. 2012. ASXL1 mutations promote myeloid transformation through loss of PRC2-mediated gene repression. Cancer Cell 22: 180-193.

Abdel-Wahab O, Gao J, Adli M, Dey A, Trimarchi T, Chung YR, Kuscu C, Hricik T, Ndiaye-Lobry D, Lafave LM, et al. 2013. Deletion of Asxl1 results in myelodysplasia and severe developmental defects in vivo. J Exp Med 210: 2641-2659.

Aravind L, Iyer LM. 2012. The HARE-HTH and associated domains: Novel modules in the coordination of epigenetic DNA and protein modifications. Cell Cycle 11: 119131.

Avila M, Kirchhoff M, Marle N, Hove HD, Chouchane M, Thauvin-Robinet C, Masurel A, Mosca-Boidron AL, Callier P, Mugneret F, et al. 2013. Delineation of a new chromosome 20q11.2 duplication syndrome including the ASXL1 gene. Am J Med Genet A 161: 1594-1598.

Bainbridge MN, Hu H, Muzny DM, Musante L, Lupski JR, Graham BH, Chen W, Gripp KW, Jenny K, Wienker TF, et al. 2013. De novo truncating mutations in ASXL3 are associated with a novel clinical phenotype with similarities to Bohring-Opitz syndrome. Genome Med 5: 11.

Balasubramani A, Larjo A, Bassein JA, Chang X, Hastie RB, Togher SM, Lahdesmaki H, Rao A. 2015. Cancer-associated ASXL1 mutations may act as gain-of-function mutations of the ASXL1-BAP1 complex. Nat Commun 6: 7307.

Baskind HA, Na L, Ma Q, Patel MP, Geenen DL, Wang QT. 2009. Functional conservation of Asxl2, a murine homo$\log$ for the Drosophila enhancer of trithorax and polycomb group gene Asx. PLoS ONE 4: e4750.

Beekman R, Valkhof MG, Sanders MA, van Strien PM, Haanstra JR, Broeders L, Geertsma-Kleinekoort WM, 
Veerman AJ, Valk PJ, Verhaak RG, et al. 2012. Sequential gain of mutations in severe congenital neutropenia progressing to acute myeloid leukemia. Blood 119: 50715077.

Bejar R, Stevenson K, Abdel-Wahab O, Galili N, Nilsson B, Garcia-Manero G, Kantarjian H, Raza A, Levine RL, Neuberg D, et al. 2011. Clinical effect of point mutations in myelodysplastic syndromes. N Engl J Med 364: 24962506.

Bott M, Brevet M, Taylor BS, Shimizu S, Ito T, Wang L, Creaney J, Lake RA, Zakowski MF, Reva B, et al. 2011. The nuclear deubiquitinase BAP1 is commonly inactivated by somatic mutations and 3p21.1 losses in malignant pleural mesothelioma. Nat Genet 43: 668-672.

Carbone M, Yang H, Pass HI, Krausz T, Testa JR, Gaudino G. 2013. BAP1 and cancer. Nat Rev Cancer 13: 153-159.

Damaj G, Joris M, Chandesris O, Hanssens K, Soucie E, Canioni D, Kolb B, Durieu I, Gyan E, Livideanu C, et al. 2014. ASXL1 but not TET2 mutations adversely impact overall survival of patients suffering systemic mastocytosis with associated clonal hematologic non-mastcell diseases. PLoS ONE 9: e85362.

Dangiolo SB, Wilson A, Jobanputra V, Anyane-Yeboa K. 2015. Bohring-Opitz syndrome (BOS) with a new ASXL1 pathogenic variant: Review of the most prevalent molecular and phenotypic features of the syndrome. Am J Med Genet A 167: 3161-3166.

Daou S, Hammond-Martel I, Mashtalir N, Barbour H, Gagnon J, Iannantuono NV, Nkwe NS, Motorina A, Pak H, $\mathrm{Yu} \mathrm{H}$, et al. 2015. The BAP1/ASXL2 histone H2A deubiquitinase complex regulates cell proliferation and is disrupted in cancer. J Biol Chem 290: 28643-28663.

Devillier R, Mansat-De Mas V, Gelsi-Boyer V, Demur C, Murati A, Corre J, Prebet T, Bertoli S, Brecqueville M, Arnoulet C, et al. 2015. Role of ASXL1 and TP53 mutations in the molecular classification and prognosis of acute myeloid leukemias with myelodysplasia-related changes. Oncotarget 6: 8388-8396.

Dey A, Seshasayee D, Noubade R, French DM, Liu J, Chaurushiya MS, Kirkpatrick DS, Pham VC, Lill JR, Bakalarski CE, et al. 2012. Loss of the tumor suppressor BAP1 causes myeloid transformation. Science 337: 1541-1546.

Dinwiddie DL, Soden SE, Saunders CJ, Miller NA, Farrow EG, Smith LD, Kingsmore SF. 2013. De novo frameshift mutation in ASXL3 in a patient with global developmental delay, microcephaly, and craniofacial anomalies. $B M C$ Med Genomics 6: 32 .

Duployez N, Micol JB, Boissel N, Petit A, Geffroy S, Bucci M, Lapillonne H, Renneville A, Leverger G, Ifrah N, et al. 2015a. Unlike ASXL1 and ASXL2 mutations, ASXL3 mutations are rare events in acute myeloid leukemia with $\mathrm{t}(8 ; 21)$. Leuk Lymphoma 57: 199-200.

Duployez N, Willekens C, Marceau-Renaut A, Boudry-Labis E, Preudhomme C. 2015b. Prognosis and monitoring of core-binding factor acute myeloid leukemia: Current and emerging factors. Exp Rev Hematol 8: 43-56.

Duployez N, Marceau-Renaut A, Boissel N, Petit A, Bucci M, Geffroy S, Lapillonne H, Renneville A, Ragu C, Figeac M, et al. 2016. Comprehensive mutational profiling of core binding factor acute myeloid leukemia. Blood 19: 24512459.
Elliott MA, Pardanani A, Hanson CA, Lasho TL, Finke CM, Belachew AA, Tefferi A. 2015. ASXL1 mutations are frequent and prognostically detrimental in CSF3R-mutated chronic neutrophilic leukemia. Am J Hematol 90: 653656.

Farber CR, Bennett BJ, Orozco L, Zou W, Lira A, Kostem E, Kang HM, Furlotte N, Berberyan A, Ghazalpour A, et al. 2011. Mouse genome-wide association and systems genetics identify Asxl2 as a regulator of bone mineral density and osteoclastogenesis. PLoS Genet 7: e1002038.

Fernandez-Mercado M, Yip BH, Pellagatti A, Davies C, Larrayoz MJ, Kondo T, Perez C, Killick S, McDonald EJ, Odero MD, et al. 2012. Mutation patterns of 16 genes in primary and secondary acute myeloid leukemia (AML) with normal cytogenetics. PLoS ONE 7: e42334.

Fisher CL, Berger J, Randazzo F, Brock HW. 2003. A human homolog of Additional sex combs, ADDITIONAL SEX COMBS-LIKE 1, maps to chromosome 20q11. Gene 306: $115-126$.

Fisher CL, Randazzo F, Humphries RK, Brock HW. 2006. Characterization of Asxl1, a murine homolog of Additional sex combs, and analysis of the Asx-like gene family. Gene 369: 109-118.

Fisher CL, Lee I, Bloyer S, Bozza S, Chevalier J, Dahl A, Bodner C, Helgason CD, Hess JL, Humphries RK, et al. 2010a. Additional sex combs-like 1 belongs to the enhancer of trithorax and polycomb group and genetically interacts with Cbx2 in mice. Dev Biol 337: 9-15.

Fisher CL, Pineault N, Brookes C, Helgason CD, Ohta H, Bodner C, Hess JL, Humphries RK, Brock HW. 2010b. Loss-of-function Additional sex combs like 1 mutations disrupt hematopoiesis but do not cause severe myelodysplasia or leukemia. Blood 115: 38-46.

Gaytan de Ayala Alonso A, Gutierrez L, Fritsch C, Papp B, Beuchle D, Muller J. 2007. A genetic screen identifies novel polycomb group genes in Drosophila. Genetics 176: 2099-2108.

Gelsi-Boyer V, Trouplin V, Adelaide J, Bonansea J, Cervera N, Carbuccia N, Lagarde A, Prebet T, Nezri M, Sainty D, et al. 2009. Mutations of polycomb-associated gene ASXL1 in myelodysplastic syndromes and chronic myelomonocytic leukaemia. Br J Haematol 145: 788-800.

Genovese G, Kahler AK, Handsaker RE, Lindberg J, Rose SA, Bakhoum SF, Chambert K, Mick E, Neale BM, Fromer M, et al. 2014. Clonal hematopoiesis and blood-cancer risk inferred from blood DNA sequence. $N$ Engl J Med 371: 2477-2487.

Grasso CS, Wu YM, Robinson DR, Cao X, Dhanasekaran SM, Khan AP, Quist MJ, Jing X, Lonigro RJ, Brenner JC, et al. 2012. The mutational landscape of lethal castrationresistant prostate cancer. Nature 487: 239-243.

Guo G, Gui Y, Gao S, Tang A, Hu X, Huang Y, Jia W, Li Z, He M, Sun L, et al. 2012. Frequent mutations of genes encoding ubiquitin-mediated proteolysis pathway components in clear cell renal cell carcinoma. Nat Genet 44: 1719.

Haferlach T, Nagata Y, Grossmann V, Okuno Y, Bacher U, Nagae G, Schnittger S, Sanada M, Kon A, Alpermann T, et al. 2014. Landscape of genetic lesions in 944 patients with myelodysplastic syndromes. Leukemia 28: 241-247.

Harbour JW, Onken MD, Roberson ED, Duan S, Cao L, Worley LA, Council ML, Matatall KA, Helms C, Bowcock 
AM. 2010. Frequent mutation of BAP1 in metastasizing uveal melanomas. Science 330: 1410-1413.

Hoischen A, van Bon BW, Rodriguez-Santiago B, Gilissen C, Vissers LE, de Vries P, Janssen I, van Lier B, Hastings R, Smithson SF, et al. 2011. De novo nonsense mutations in ASXL1 cause Bohring-Opitz syndrome. Nat Genet 43: 729-731.

Huether R, Dong L, Chen X, Wu G, Parker M, Wei L, Ma J, Edmonson MN, Hedlund EK, Rusch MC, et al. 2014. The landscape of somatic mutations in epigenetic regulators across 1,000 paediatric cancer genomes. Nat Commun 5: 3630.

Inoue D, Kitaura J, Togami K, Nishimura K, Enomoto Y, Uchida T, Kagiyama Y, Kawabata KC, Nakahara F, Izawa $\mathrm{K}$, et al. 2013. Myelodysplastic syndromes are induced by histone methylation-altering ASXL1 mutations. J Clin Invest 123: 4627-4640.

Inoue D, Nishimura K, Kozuka-Hata H, Oyama M, Kitamura T. 2015. The stability of epigenetic factor ASXL1 is regulated through ubiquitination and USP7-mediated deubiquitination. Leukemia 29: 2257-2260.

Itzykson R, Kosmider O, Renneville A, Gelsi-Boyer V, Meggendorfer M, Morabito M, Berthon C, Ades L, Fenaux P, Beyne-Rauzy O, et al. 2013. Prognostic score including gene mutations in chronic myelomonocytic leukemia. $J$ Clin Oncol 31: 2428-2436.

Izawa T, Rohatgi N, Fukunaga T, Wang QT, Silva MJ, Gardner MJ, McDaniel ML, Abumrad NA, Semenkovich CF, Teitelbaum SL, et al. 2015. ASXL2 regulates glucose, lipid, and skeletal homeostasis. Cell Rep 11: 1625-1637.

Jaiswal S, Fontanillas P, Flannick J, Manning A, Grauman PV, Mar BG, Lindsley RC, Mermel CH, Burtt N, Chavez A, et al. 2014. Age-related clonal hematopoiesis associated with adverse outcomes. N Engl J Med 371: 2488-2498.

Jensen DE, Proctor M, Marquis ST, Gardner HP, Ha SI, Chodosh LA, Ishov AM, Tommerup N, Vissing H, Sekido Y, et al. 1998. BAP1: A novel ubiquitin hydrolase which binds to the BRCA1 RING finger and enhances BRCA1mediated cell growth suppression. Oncogene 16: 10971112.

Katoh M. 2013. Functional and cancer genomics of ASXL family members. Br J Cancer 109: 299-306.

Katoh M. 2015. Functional proteomics of the epigenetic regulators ASXL1, ASXL2 and ASXL3: A convergence of proteomics and epigenetics for translational medicine. Expert Rev Proteomics 12: 317-328.

Katoh M, Katoh M. 2003. Identification and characterization of ASXL2 gene in silico. Int J Oncol 23: 845-850.

LaFave LM, Beguelin W, Koche R, Teater M, Spitzer B, Chramiec A, Papalexi E, Keller MD, Hricik T, Konstantinoff K, et al. 2015. Loss of BAP1 function leads to EZH2-dependent transformation. Nat Med 21: 1344-1349.

Lai HL, Wang QT. 2013. Additional sex combs-like 2 is required for polycomb repressive complex 2 binding at select targets. PLoS ONE 8: e73983.

Lai HL, Grachoff M, McGinley AL, Khan FF, Warren CM, Chowdhury SA, Wolska BM, Solaro RJ, Geenen DL, Wang QT. 2012. Maintenance of adult cardiac function requires the chromatin factor Asxl2. J Mol Cell Cardiol 53: $734-741$.
Magini P, Della Monica M, Uzielli ML, Mongelli P, Scarselli G, Gambineri E, Scarano G, Seri M. 2012. Two novel patients with Bohring-Opitz syndrome caused by de novo ASXL1 mutations. Am J Med Genet A 158: 917-921.

Mallery DL, Vandenberg CJ, Hiom K. 2002. Activation of the E3 ligase function of the BRCA1/BARD1 complex by polyubiquitin chains. EMBO J 21: 6755-6762.

McGinley AL, Li Y, Deliu Z, Wang QT. 2014. Additional sex combs-like family genes are required for normal cardiovascular development. Genesis 52: 671-686.

Metzeler KH, Becker H, Maharry K, Radmacher MD, Kohlschmidt J, Mrozek K, Nicolet D, Whitman SP, Wu YZ, Schwind S, et al. 2011. ASXL1 mutations identify a high-risk subgroup of older patients with primary cytogenetically normal AML within the ELN Favorable genetic category. Blood 118: 6920-6929.

Micol JB, Abdel-Wahab O. 2014. Collaborating constitutive and somatic genetic events in myeloid malignancies: ASXL1 mutations in patients with germline GATA2 mutations. Haematologica 99: 201-203.

Micol JB, Duployez N, Boissel N, Petit A, Geffroy S, Nibourel O, Lacombe C, Lapillonne H, Etancelin P, Figeac M, et al. 2014. Frequent ASXL2 mutations in acute myeloid leukemia patients with $\mathrm{t}(8 ; 21) / R U N X 1$ RUNX1T1 chromosomal translocations. Blood 124: 1445-1449.

Micol JB, Duployez N, Pastore A, Williams R, Kim E, Lee S, Durham B, Chung YR, Cho H, Preudhomme C, AbdelWahab O. 2015. ASXL2 is a novel mediator of RUNX1ETO transcriptional function and collaborates with RUNX1-ETO to promote leukemogenesis. 57th ASH Annual Meeting and Exposition, Abstract 302. Orlando, FL, December 5-8.

Milne TA, Sinclair DA, Brock HW. 1999. The Additional sex combs gene of Drosophila is required for activation and repression of homeotic loci, and interacts specifically with Polycomb and super sex combs. Mol Gen Genet 261: 753-761.

Moon S, Um SJ, Kim EJ. 2015. Role of Asxl1 in kidney podocyte development via its interaction with Wtip. Biochem Biophys Res Commun 466: 560-566.

Park UH, Yoon SK, Park T, Kim EJ, Um SJ. 2011. Additional sex comb-like (ASXL) proteins 1 and 2 play opposite roles in adipogenesis via reciprocal regulation of peroxisome proliferator-activated receptor $\gamma$. J Biol Chem 286: 13541363.

Park UH, Kang MR, Kim EJ, Kwon YS, Hur W, Yoon SK, Song BJ, Park JH, Hwang JT, Jeong JC, et al. 2015. ASXL2 promotes proliferation of breast cancer cells by linking $\mathrm{ER} \alpha$ to histone methylation. Oncogene doi: 10.1038/ onc.2015.443.

Patel JP, Gonen M, Figueroa ME, Fernandez H, Sun Z, Racevskis J, Van Vlierberghe P, Dolgalev I, Thomas S, Aminova O, et al. 2012. Prognostic relevance of integrated genetic profiling in acute myeloid leukemia. $N$ Engl J Med 366: 1079-1089.

Prebet T, Carbuccia N, Raslova H, Favier R, Rey J, Arnoulet C, Vey N, Vainchenker W, Birnbaum D, Mozziconacci MJ. 2013. Concomitant germ-line RUNX1 and acquired ASXL1 mutations in a T-cell acute lymphoblastic leukemia. Eur J Haematol 91: 277-279. 
J.-B. Micol and O. Abdel-Wahab

Quesada V, Conde L, Villamor N, Ordonez GR, Jares P, Bassaganyas L, Ramsay AJ, Bea S, Pinyol M, MartinezTrillos A, et al. 2012. Exome sequencing identifies recurrent mutations of the splicing factor SF3B1 gene in chronic lymphocytic leukemia. Nat Genet 44: 47-52.

Russell B, Graham JM Jr. 2013. Expanding our knowledge of conditions associated with the ASXL gene family. Genome Med 5: 16.

Russell B, Johnston JJ, Biesecker LG, Kramer N, Pickart A, Rhead W, Tan WH, Brownstein CA, Kate Clarkson L, Dobson A, et al. 2015. Clinical management of patients with ASXL1 mutations and Bohring-Opitz syndrome, emphasizing the need for Wilms tumor surveillance. Am J Med Genet A 167: 2122-2131.

Sahtoe DD, van Dijk WJ, Ekkebus R, Ovaa H, Sixma TK. 2016. BAP1/ASXL1 recruitment and activation for H2A deubiquitination. Nat Commun 7: 10292.

Sanchez-Pulido L, Kong L, Ponting CP. 2012. A common ancestry for BAP1 and Uch37 regulators. Bioinformatics 28: $1953-1956$.

Scheuermann JC, de Ayala Alonso AG, Oktaba K, Ly-Hartig N, McGinty RK, Fraterman S, Wilm M, Muir TW, Muller J. 2010. Histone H2A deubiquitinase activity of the Polycomb repressive complex PR-DUB. Nature 465: 243247.

Sinclair DA, Milne TA, Hodgson JW, Shellard J, Salinas CA, Kyba M, Randazzo F, Brock HW. 1998. The additional sex combs gene of Drosophila encodes a chromatin protein that binds to shared and unique Polycomb group sites on polytene chromosomes. Development 125: 1207-1216.

Srivastava A, Ritesh KC, Tsan YC, Liao R, Su F, Cao X, Hannibal MC, Keegan CE, Chinnaiyan AM, Martin DM, et al. 2015. De novo dominant ASXL3 mutations alter $\mathrm{H} 2 \mathrm{~A}$ deubiquitination and transcription in Bainbridge-Ropers syndrome. Hum Mol Genet 25: 597-608.

Stein BL, Williams DM, O'Keefe C, Rogers O, Ingersoll RG, Spivak JL, Verma A, Maciejewski JP, McDevitt MA, Moliterno AR. 2011. Disruption of the ASXL1 gene is frequent in primary, post-essential thrombocytosis and post-polycythemia vera myelofibrosis, but not essential thrombocytosis or polycythemia vera: Analysis of molecular genetics and clinical phenotypes. Haematologica 96: $1462-1469$.
Testa JR, Cheung M, Pei J, Below JE, Tan Y, Sementino E, Cox NJ, Dogan AU, Pass HI, Trusa S, et al. 2011. Germline BAP1 mutations predispose to malignant mesothelioma. Nat Genet 43: 1022-1025.

Thol F, Friesen I, Damm F, Yun H, Weissinger EM, Krauter J, Wagner K, Chaturvedi A, Sharma A, Wichmann M, et al. 2011. Prognostic significance of ASXL1 mutations in patients with myelodysplastic syndromes. J Clin Oncol 29: 2499-2506.

Valletta S, Dolatshad H, Bartenstein M, Yip BH, Bello E, Gordon S, Yu Y, Shaw J, Roy S, Scifo L, et al. 2015. ASXL1 mutation correction by CRISPR/Cas9 restores gene function in leukemia cells and increases survival in mouse xenografts. Oncotarget 6: 44061-44071.

Wang J, Li Z, He Y, Pan F, Chen S, Rhodes S, Nguyen L, Yuan J, Jiang L, Yang X, et al. 2014. Loss of Asxl1 leads to myelodysplastic syndrome-like disease in mice. Blood 123: $541-553$.

West RR, Hsu AP, Holland SM, Cuellar-Rodriguez J, Hickstein DD. 2014. Acquired ASXL1 mutations are common in patients with inherited GATA2 mutations and correlate with myeloid transformation. Haematologica 99: 276-281.

Wiesner T, Obenauf AC, Murali R, Fried I, Griewank KG, Ulz P, Windpassinger C, Wackernagel W, Loy S, Wolf I, et al. 2011. Germline mutations in BAP1 predispose to melanocytic tumors. Nat Genet 43: 1018-1021.

Wu X, Bekker-Jensen IH, Christensen J, Rasmussen KD, Sidoli S, Qi Y, Kong Y, Wang X, Cui Y, Xiao Z, et al. 2015. Tumor suppressor ASXL1 is essential for the activation of INK4B expression in response to oncogene activity and anti-proliferative signals. Cell Res 25: 12051218.

Xie M, Lu C, Wang J, McLellan MD, Johnson KJ, Wendl MC, McMichael JF, Schmidt HK, Yellapantula V, Miller CA, et al. 2014. Age-related mutations associated with clonal hematopoietic expansion and malignancies. Nat Med 20: $1472-1478$.

Yoshizato T, Dumitriu B, Hosokawa K, Makishima H, Yoshida K, Townsley D, Sato-Otsubo A, Sato Y, Liu D, Suzuki H, et al. 2015. Somatic mutations and clonal hematopoiesis in aplastic anemia. $N$ Engl J Med 373: 35-47. 


\section{$\& \mathrm{CSH} \&$ Cold Spring Harbor

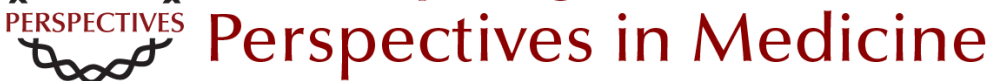

\section{The Role of Additional Sex Combs-Like Proteins in Cancer}

Jean-Baptiste Micol and Omar Abdel-Wahab

Cold Spring Harb Perspect Med 2016; doi: 10.1101/cshperspect.a026526 originally published online August 15, 2016

\section{Subject Collection Chromatin Deregulation in Cancer}

\section{Mixed-Lineage Leukemia Fusions and Chromatin in Leukemia \\ Andrei V. Krivtsov, Takayuki Hoshii and Scott A. Armstrong}

Targeting Cancer Cells with BET Bromodomain Inhibitors

Yali Xu and Christopher R. Vakoc

The Role of Nuclear Receptor-Binding SET

Domain Family Histone Lysine Methyltransferases

in Cancer

Richard L. Bennett, Alok Swaroop, Catalina Troche, et al.

SETting the Stage for Cancer Development:

SETD2 and the Consequences of Lost Methylation Catherine C. Fahey and lan J. Davis

ATRX and DAXX: Mechanisms and Mutations Michael A. Dyer, Zulekha A. Qadeer, David Valle-Garcia, et al.

DNMT3A in Leukemia

Lorenzo Brunetti, Michael C. Gundry and Margaret A. Goodell

Oncogenic Mechanisms of Histone H3 Mutations Daniel N. Weinberg, C. David Allis and Chao Lu

Nonhistone Lysine Methylation in the Regulation of Cancer Pathways

Scott M. Carlson and Or Gozani
TET2 in Normal and Malignant Hematopoiesis Robert L. Bowman and Ross L. Levine

Long Noncoding RNAs: At the Intersection of Cancer and Chromatin Biology Adam M. Schmitt and Howard Y. Chang

DNA Hypomethylating Drugs in Cancer Therapy Takahiro Sato, Jean-Pierre J. Issa and Patricia Kropf

The Chromodomain Helicase DNA-Binding Chromatin Remodelers: Family Traits that Protect from and Promote Cancer Alea A. Mills

Exploitation of EP300 and CREBBP Lysine Acetyltransferases by Cancer Narsis Attar and Siavash K. Kurdistani

Histone Lysine Demethylase Inhibitors Ashwini Jambhekar, Jamie N. Anastas and Yang Shi

Cohesin Mutations in Cancer Magali De Koninck and Ana Losada

MLL3/MLL4/COMPASS Family on Epigenetic Regulation of Enhancer Function and Cancer Christie C. Sze and Ali Shilatifard

For additional articles in this collection, see http://perspectivesinmedicine.cshlp.org/cgi/collection/ 